\title{
Model Prediksi Kelulusan Mahasiswa Menggunakan Decision Tree C4.5 dan Software Weka
}

\author{
Isnan Mulia ${ }^{1}$, Muanas ${ }^{2}$ \\ DOI: https://doi.org/10.36339/jaspt.v5i1.417
}

\begin{abstract}
In this research, we build a model to predict graduation status of students in Institut Bisnis dan Informatika Kesatuan using C4.5 decision tree algorithm. The prediction model is built using students' GPA from semester 1 to semester 4, for students with admission year of 2013 to 2016. The prediction model obtained is a decision tree with 26 rules, with the attribute IPS_4 being the attribute that determines the graduation label of students. This prediction model yields an accuracy of $73 \%$, a result that is not good enough. This result is probably due to unbalanced proportion of the data used.
\end{abstract}

Keywords: data mining, graduation prediction, C4.5 algorithm, Weka

\begin{abstract}
Abstrak
Dalam penelitian inl dibangun sebuah model untuk memprediksi status kelulusan mahasiswa Institut Bisnis dan Informatika Kesatuan menggunakan algoritma pohon keputusan C4.5. Model prediksi dibangun dengan menggunakan IPK mahasiswa semester 1 sampai semester 4, untuk mahasiswa tahun masuk 2013 sampai 2016. Model prediksi yang didapat adalah pohon keputusan dengan 26 aturan, dengan atribut IPS_4 menjadi atribut yang menentukan label kelulusan dari siswa. Model prediksi ini menghasilkan akurasi sebesar $73 \%$, hasil yang kurang baik. Hasil ini kemungkinan disebabkan oleh proporsi data yang digunakan tidak seimbang.
\end{abstract}

Kata Kunci: data mining, prediksi kelulusan, algoritma C4.5, Weka

\section{PENDAHULUAN}

Pendidikan pada jenjang strata 1 (S1) di Indonesia pada umumnya ditempuh selama 4 tahun akademik, dengan batas maksimal 7 tahun akademik (Kementerian Pendidikan dan Kebudayaan Republik Indonesia 2020). Jika seorang mahasiswa berhasil menyelesaikan pendidikan $\mathrm{S} 1$ dalam rentang waktu 4 tahun, mahasiswa tersebut dapat dinyatakan lulus tepat waktu. Jika tidak, maka mahasiswa tersebut dinyatakan tidak lulus tepat waktu.

Ada beberapa faktor yang dapat mempengaruhi apakah seorang mahasiswa dapat menyelesaikan pendidikan S1 dalam waktu yang sudah ditentukan atau tidak. Suhaimi et al. (2019) mengelompokkan faktor-faktor tersebut menjadi lima kelompok, yaitu kelompok faktor internal, kelompok faktor akademik, kelompok faktor keluarga, kelompok

1. Program Studi Sistem Informasi, Institut Bisnis dan Informatika Kesatuan

2. Progran Studi Akuntansi, Insititut Bisnis dan Informatika Kesatuan, Jalan Ranggagading No. 1 Bogor West Java, Indonesia

Email of Corresponding Author : isnan.mulia@ibik.ac.id

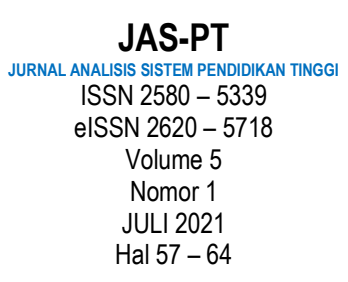

DOSEN INDONESIA SEMESTA 
faktor tempat tinggal, dan kelompok faktor perilaku. Detail dari kelima kelompok faktor ditunjukkan pada Tabel 1.

Tabel 1 Kelompok faktor yang mempengaruhi kelulusan mahasiswa, (Suhaimi,2019)

\begin{tabular}{|l|l|}
\hline Kelompok Faktor & \multicolumn{1}{|c|}{ Detail Kelompok Faktor } \\
\hline Internal & $\begin{array}{l}\text { Jenis kelamin, umur, status pernikahan, status hubungan, } \\
\text { kondisi Kesehatan }\end{array}$ \\
\hline Akademik & Indeks prestasi, indeks prestasi kumulatif, tingkat pendidikan \\
\hline Keluarga & Tingkat pendidikan orang tua, pekerjaan orang tua \\
\hline Tempat tinggal & Kediaman keluarga, jarak perjalanan dari kediaman ke kampus \\
\hline Perilaku & $\begin{array}{l}\text { Waktu yang digunakan untuk ponsel dan internet, konsumsi } \\
\text { alkohol, waktu yang digunakan untuk belajar, minat terhadap } \\
\text { studi }\end{array}$ \\
\hline
\end{tabular}

Data mining merupakan proses menemukan pola pada suatu data dengan cara menganalisis data tersebut. Prosesnya dapat dilakukan secara otomatis atau semiotomatis, dan pola yang ditemukan harus bermakna dan dapat mengarah pada sebuah kesimpulan yang dapat menguntungkan bagi organisasi yang memiliki data tersebut (Witten et al. 2011). Proses yang dilakukan untuk dapat menemukan pola dari data di antaranya adalah pembersihan data (data cleaning), praproses data (data preprocessing), penambangan data (data mining), dan evaluasi pola (pattern evaluation) (Han et al. 2012).

Beberapa penelitian menggunakan pendekatan data mining untuk memprediksi kelulusan mahasiswa. Solichin (2019) membandingkan tiga buah metode untuk memprediksi kelulusan mahasiswa, yaitu decision tree, Naïve Bayes, dan K-Nearest Neighbor, dengan hasil klasifikasi terbaik didapat oleh K-Nearest Neighbor. Al Amin et al. (2013) menggunakan pohon klasifikasi CART untuk menganalisis karakteristik mahasiswa dua fakultas di IPB sebagai indikator ketepatan waktu lulus. Kurniawan et al. (2020) membangun sistem untuk memprediksi kelulusan mahasiswa berdasarkan model prediksi yang dibangun dengan menggunakan algoritme decision tree $\mathrm{C} 4.5$ dan data dengan atribut jenis kelamin, asal SMA, dan indeks prestasi untuk beberapa semester awal.

Pada penelitian ini, dibangun sebuah model prediksi untuk memprediksi status kelulusan mahasiswa pada Institut Bisnis dan Informatika (IBI) Kesatuan dengan menggunakan algoritme decision tree $\mathrm{C} 4.5$, berdasarkan data prestasi akademik mahasiswa pada beberapa semester awal. Model prediksi ini diharapkan dapat membantu pihak program studi untuk mendeteksi dan mendorong mahasiswa yang terprediksi tidak lulus tepat waktu, agar dapat lulus tepat pada waktunya

\section{METODE PENELITIAN}

Data yang digunakan pada penelitian ini adalah data prestasi akademik mahasiswa program studi S1 Akuntansi dan S1 Manajemen dengan tahun masuk 2013 sampai dengan 2016. Data tersebut didapatkan dari bagian akademik IBI Kesatuan. Atribut data yang tersedia di antaranya adalah jenis kelamin, program studi, tanggal masuk, indeks

JAS-PT

JURNAL ANALISIS SISTEM PENDIDIKAN TINGGI

ISSN $2580-5339$

eISSN $2620-5718$

Volume 5

Nomor 1

JULI 2021

Hal $57-64$

DOSEN INDONESIA SEMESTA prestasi per semester, tanggal lulus, dan lama studi dari masing-masing mahasiswa.

Model prediksi dibangun menggunakan algoritme decision tree C4.5. Algoritme ini pertama kali diajukan oleh Quinlan pada tahun 1993, dan kemudian ditingkatkan fungsinya pada tahun 1996 (Quinlan 1996). Secara umum, decision tree merupakan sebuah struktur pohon yang mirip dengan diagram alir (flowchart), di mana node internal menunjukkan pengujian terhadap suatu atribut, setiap cabang mewakili luaran dari uji 
atribut tersebut, dan setiap node daun (leaf node) memegang label kelas. Dalam membangun sebuah decision tree, tidak diperlukan pengetahuan khusus dalam suatu bidang ilmu maupun pengaturan parameter, sehingga metode ini sesuai untuk proses penemuan pengetahuan (knowledge discovery) (Han et al. 2012). Contoh decision tree sederhana ditunjukkan pada Gambar 1.

Proses membangun model prediksi dilakukan dengan bantuan software Weka, sebuah program aplikasi yang menyediakan berbagai kakas (tools) untuk melakukan berbagai pekerjaan dalam ranah data mining. Tugas yang dapat dilakukan pada Weka di antaranya adalah menyiapkan data masukan, mengevaluasi skema pembelajaran secara statistik, serta memvisualisasikan data masukan dan hasil pembelajaran. Metode data mining yang didukung oleh Weka di antaranya adalah regresi, klasifikasi, clustering, association rule mining, dan pemilihan atribut (Frank et al. 2009). Nafie Ali (2018) menggunakan Weka untuk menggali aturan yang didapatkan dari data kecelakaan lalu lintas yang terjadi di provinsi Alghat, Arab Saudi, dengan bantuan algoritma association rule mining dan clustering. Sementara itu, Meiriza et al. (2020) menggunakan Weka untuk memprediksi kelulusan mahasiswa program studi Sistem Informasi, fakultas IImu Komputer, Universitas Sriwijaya dengan menggunakan Naïve Bayes.

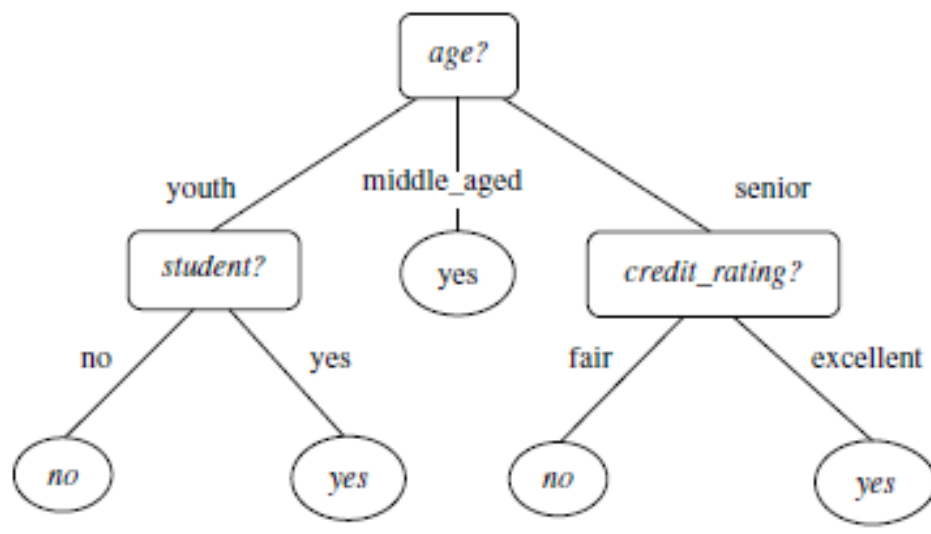

Gambar 1 Contoh decision tree sederhana (Han et al. 2012)

\section{HASIL DAN PEMBAHASAN}

\section{Praproses Data}

Dari data yang sudah didapatkan, pertama dilakukan penentuan kriteria kelulusan mahasiswa, apakah lulus tepat waktu, lulus agak terlambat, atau lulus terlambat. Kriteria kelulusan mahasiswa ini menjadi label kelas target bagi data. Penentuan ketiga kriteria ini didasarkan pada lama studi, yang didapat dari selisih antara tanggal lulus dengan tanggal masuk. Jika lama studi kurang dari atau sama dengan 4 tahun (1.461 hari), maka mahasiswa dinyatakan lulus tepat waktu. Jika lama studi lebih dari 4 tahun (1.461 hari) dan kurang dari atau sama dengan 5 tahun (1.827 hari), maka mahasiswa dinyatakan lulus agak terlambat. Jika lama studi lebih dari 5 tahun (1.827 hari), maka mahasiswa dinyatakan lulus terlambat.

Pada langkah berikutnya, dilakukan penghapusan atribut yang tidak diperlukan. Secara umum, prediksi kelulusan mahasiswa diharapkan dapat dilakukan sedini mungkin, agar pihak program studi dapat mempersiapkan langkah-langkah yang perlu dilakukan untuk mengantisipasi terlambatnya kelulusan mahasiswa. Oleh karena itu, pada penelitian ini data nilai yang digunakan hanya indeks prestasi mahasiswa dari semester 1 sampai dengan semester 4. Atribut yang dihapus di antaranya adalah atribut NPM, nama

JAS-PT

JURNAL ANALISIS SISTEM PENDIDIKAN TINGGI ISSN $2580-5339$ elSSN $2620-5718$

Volume 5

Nomor 1

JULI 2021

Hal $57-64$

DOSEN INDONESIA SEMESTA 
mahasiswa, tahun masuk, indeks prestasi untuk semester di atas semester 4 , tanggal masuk, dan tanggal lulus.

Berikutnya, dilakukan pengubahan tipe data untuk atribut indeks prestasi semester 1 sampai dengan indeks prestasi semester 4, dari tipe numerik menjadi kategorik. Pengubahan tipe data dilakukan agar tipe data untuk atribut indeks prestasi sama dengan tipe data untuk atribut lainnya. Kriteria yang digunakan untuk atribut indeks prestasi mengikuti predikat kelulusan mahasiswa yang ditetapkan oleh Kementerian Pendidikan dan Kebudayaan, melalui Peraturan Menteri Pendidikan dan Kebudayaan (Permendikbud) nomor 3 tahun 2020 tentang Standar Nasional Pendidikan Tinggi (Kementerian Pendidikan dan Kebudayaan Republik Indonesia 2020). Kriteria yang dimaksud ditampilkan pada Tabel 1. Karena pada Permendikbud tersebut tidak mencantumkan predikat yang diberikan untuk mahasiswa dengan IPK kurang dari atau sama dengan 2,75, maka digunakan predikat "Cukup" dan "Drop Out" untuk dua kriteria terakhir, yaitu untuk mahasiswa dengan IPK di antara 2 dan 2,75, serta untuk mahasiswa dengan IPK di bawah 2.

Hasil akhir tahapan praproses data adalah data yang siap untuk diproses, dengan jumlah atribut sebanyak 7 buah. Data terdiri dari 448 baris, dengan label kelas target TepatWaktu sebanyak 319 buah, Agak-Terlambat sebanyak 101 buah, dan Terlambat sebanyak 28 buah. Ketujuh atribut tersebut beserta tipe data dan nilai yang digunakan ditunjukkan pada Tabel 2.

Tabel 1 Predikat kelulusan mahasiswa berdasarkan Permendikbud nomor 3 tahun 2020 (Kementerian Pendidikan dan Kebudayaan Republik Indonesia 2020)

\begin{tabular}{|l|l|}
\hline \multicolumn{1}{|c|}{ Kriteria Kelulusan } & \multicolumn{1}{c|}{ Predikat } \\
\hline $\mathrm{IPK}>3,5$ & Pujian \\
\hline $\mathrm{IPK}>3$ dan IPK $\leq 3,5$ & Sangat Memuaskan \\
\hline $\mathrm{IPK}>2,75$ dan IPK $\leq 3$ & Memuaskan \\
\hline $\mathrm{IPK} \geq 2$ dan IPK $\leq 2,75$ & Cukup $^{*}$ \\
\hline $\mathrm{IPK}<2$ & Drop Out $^{*}$ \\
\hline
\end{tabular}

Tabel 2 Atribut data setelah tahapan praproses

\begin{tabular}{|c|c|c|}
\hline Atribut & $\begin{array}{l}\text { Tipe } \\
\text { Data }\end{array}$ & Nilai \\
\hline JK & kategorik & $L, P$ \\
\hline Prodi & kategorik & 111,121 \\
\hline IPS_1 & kategorik & $\begin{array}{l}\text { Pujian, Sangat-Memuaskan, Memuaskan, Cukup, } \\
\text { Drop-Out }\end{array}$ \\
\hline IPS_2 & kategorik & $\begin{array}{l}\text { Pujian, Sangat-Memuaskan, Memuaskan, Cukup, } \\
\text { Drop-Out }\end{array}$ \\
\hline IPS_3 & kategorik & $\begin{array}{l}\text { Pujian, Sangat-Memuaskan, Memuaskan, Cukup, } \\
\text { Drop-Out }\end{array}$ \\
\hline IPS_4 & kategorik & $\begin{array}{l}\text { Pujian, Sangat-Memuaskan, Memuaskan, Cukup, } \\
\text { Drop-Out }\end{array}$ \\
\hline Status_Lulus & kategorik & Tepat-Waktu, Agak-Terlambat, Terlambat \\
\hline
\end{tabular}

\section{Model Prediksi}

Proses pembangunan model prediksi dilakukan pada software Weka, dengan menggunakan algoritme decision tree $\mathrm{C} 4.5$, yang diimplementasikan melalui library J48. Pembagian data untuk proses pelatihan/training dan pengujian/testing dilakukan 
menggunakan $k$-fold cross validation, dengan nilai $k$ sebesar 10 . Contoh data yang diproses oleh Weka ditunjukkan pada Gambar 2.

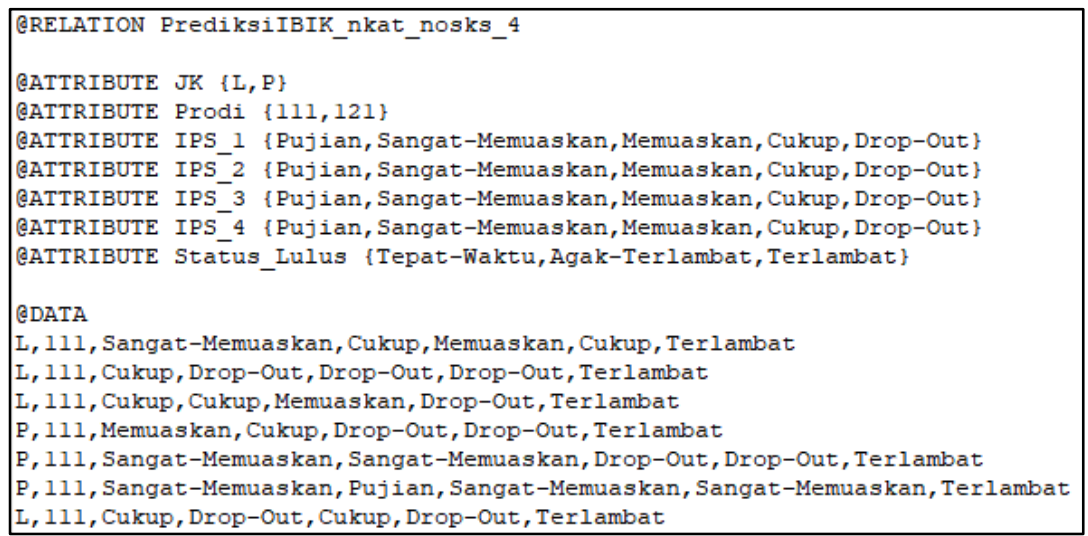

Gambar 2 Contoh data hasil praproses yang sudah disesuaikan dengan format pada Weka

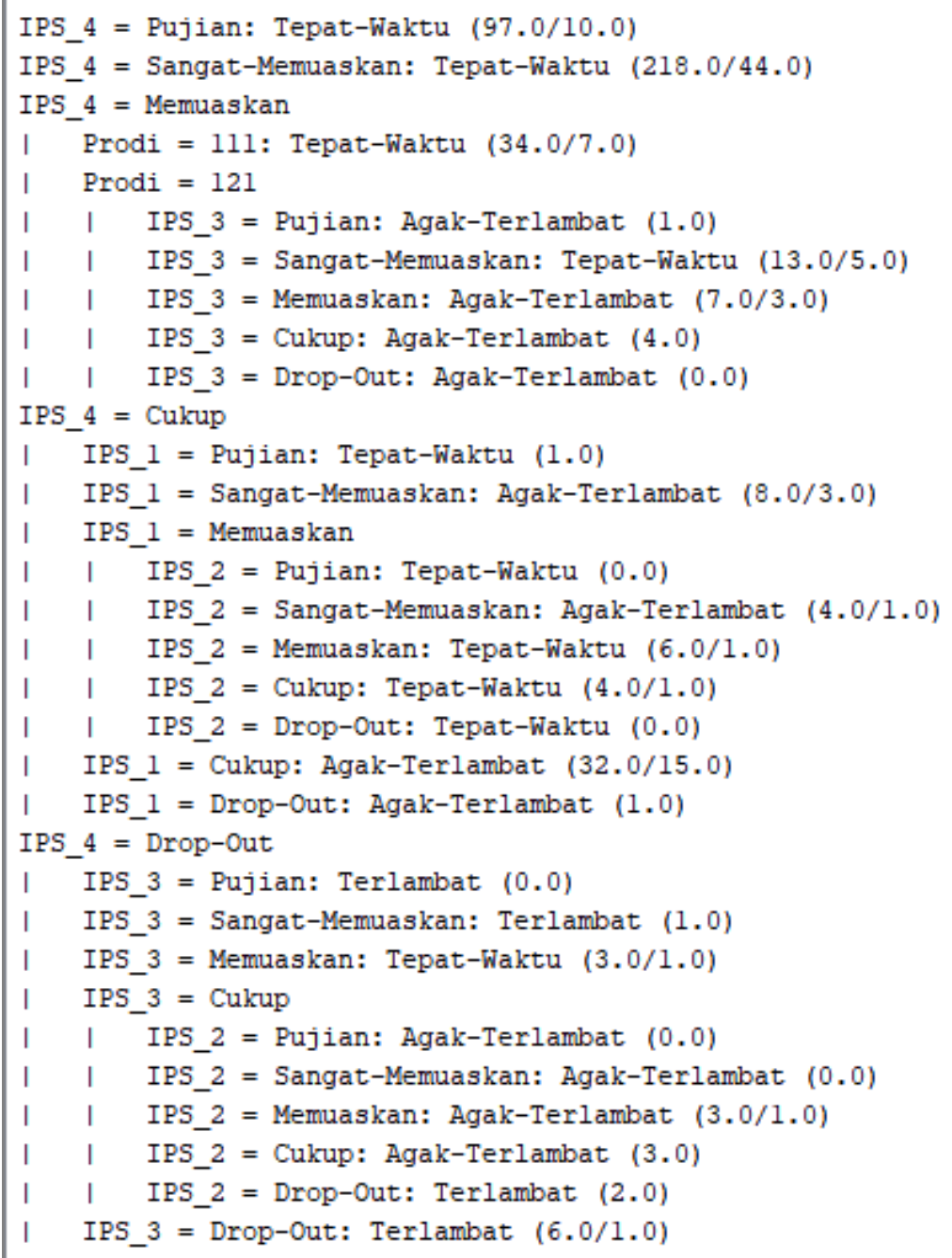

Gambar 3 Aturan/rules yang didapatkan dari model prediksi

Proses pembangunan model prediksi menghasilkan sebuah decision tree dengan jumlah daun/leaves sebanyak 26 buah dan ukuran pohon sebesar 33. Jumlah daun menunjukkan jumlah aturan/rules yang dihasilkan oleh decision tree tersebut. Dari aturan yang didapatkan, dapat dilihat bahwa atribut IPS_4 (indeks prestasi pada semester 4)

JAS-PT

JURNAL ANALISIS SISTEM PENDIDIKAN TINGGI ISSN $2580-5339$ eISSN $2620-5718$ Volume 5 Nomor 1 JULI 2021 Hal 57 - 64 DOSEN INDONESIA SEMESTA 
adalah atribut yang sangat menentukan label kelas kelulusan mahasiswa. Sementara itu, atribut JK (jenis kelamin) tidak berpengaruh terhadap penentuan label kelas kelulusan. Aturan-aturan dari decision tree ditampilkan pada Gambar 3.

\section{Pengujian Model Prediksi}

Dari hasil pengujian terhadap model prediksi yang telah didapatkan pada proses pelatihan, sebanyak 327 buah data berhasil diklasifikasikan dengan benar, sementara terdapat 121 buah data yang diklasifikasikan dengan salah. Secara keseluruhan, akurasi yang didapatkan untuk model prediksi yang telah dibangun adalah $73 \%$. Hasil klasifikasi ini dapat dikatakan tidak cukup baik, karena akurasi yang didapatkan hanya sekitar 70 persen. Hal ini mungkin disebabkan oleh proporsi data pada ketiga kelas yang digunakan dalam proses pembangunan model prediksi kurang seimbang, atau atribut data yang digunakan untuk membangun model prediksi kurang merepresentasikan kondisi yang sebenarnya. Confusion matrix dan detail pengukuran akurasi untuk ketiga label kelas disajikan pada Tabel 3 dan Tabel 4.

Tabel 3 Confusion matrix hasil prediksi

\begin{tabular}{|c|c|c|c|c|}
\hline & \multicolumn{3}{|c|}{ Kelas Prediksi } \\
\hline & & Tepat-Waktu & Agak-Terlambat & Terlambat \\
\hline \multirow{3}{*}{$\begin{array}{l}\text { Kelas } \\
\text { Asli }\end{array}$} & Tepat-Waktu & 293 & 23 & 3 \\
\hline & Aqak-Terlambat & 71 & 27 & 3 \\
\hline & Terlambat & 9 & 12 & 7 \\
\hline
\end{tabular}

Tabel 4 Statistik detail untuk ketiga label kelas

\begin{tabular}{|l|r|r|r|r|r|}
\hline \multicolumn{1}{|c|}{ Kelas } & TP Rate & \multicolumn{1}{c|}{ FP Rate } & \multicolumn{1}{c|}{ Precision } & \multicolumn{1}{c|}{ Recall } & \multicolumn{1}{c|}{ F-Measure } \\
\hline Tepat-Waktu & 0,918 & 0,620 & 0,786 & 0,918 & 0,847 \\
\hline Agak-Terlambat & 0,267 & 0,101 & 0,435 & 0,267 & 0,331 \\
\hline Terlambat & 0,250 & 0,014 & 0,538 & 0,250 & 0,341 \\
\hline
\end{tabular}

\section{SIMPULAN DAN SARAN}

Pada penelitian ini, telah dibangun sebuah model untuk memprediksi status kelulusan mahasiswa dengan menggunakan algoritme decision tree C4.5. Data yang digunakan sebagai masukan untuk model memiliki tujuh buah atribut. Model prediksi tersebut menghasilkan akurasi sebesar $73 \%$, yang dapat digolongkan sebagai hasil yang tidak cukup baik.

Model prediksi yang dibangun pada penelitian ini memiliki hasil yang kurang baik. Agar hasil prediksi yang didapat dapat lebih baik, disampaikan rekomendasi sebagai berikut.

1. Pembangunan model prediksi kelulusan mahasiswa pada penelitian berikutnya dapat melibatkan atribut data yang lebih merepresentasikan kondisi mahasiswa yang sebenarnya, misalnya menggunakan atribut indeks prestasi pada semester 5 dan 6 .

2. Pada penelitian berikutnya dapat menggunakan metode yang lain, misalnya $K$ Nearest Neighbor, Neural Network, atau Support Vector Machine.

JAS-PT

JURNAL ANALISIS SISTEM PENDIDIKAN TING ISSN $2580-5339$ eISSN $2620-5718$

Volume 5

Nomor 1

JULI 2021

Hal $57-64$

DOSEN INDONESIA SEMESTA

\section{DAFTAR PUSTAKA}

Amin, Fira Nurahmah Al, Indahwati, and Yenni Angraini. 2013. "Analisis Ketepatan Waktu Lulus Berdasarkan Karakteristik Mahasiswa FEM Dan Faperta Menggunakan Metode Chart." Xplore: Journal of Statistics 1 (2): 1-8. https://doi.org/10.29244/xplore.v1i2.12411.

Amyar, F., Hidayah, N. N., Lowe, A., \& Woods, M. (2019). Investigating the backstage of 
audit engagements: the paradox of team diversity. Accounting, Auditing \& Accountability Journal.

Ajmi, D. N., \& Iriyadi, I. (2018). Analisis Penentuan Tarif Rawat Inap dan Perhitungan Harga Pokok Pada Klinik Utama Rawat Inap dr. Yati Zarnudji. Jurnal IImiah Akuntansi Kesatuan, 6(3), 227-238.

Amanda, A. L., Efrianti, D., \& Marpaung, B. (2019). Analisis Pengaruh Kandungan Informasi Komponen Laba Dan Rugi Terhadap Koefisien Respon Laba (Erc) Studi Empiris Pada Perusahaan Manufaktur Sektor Industri Dasar Dan Kimia Yang Terdaftar Di Bursa Efek Indonesia (Bei). Jurnal IImiah Manajemen Kesatuan, 7(1), 188-200.

Astrini, D. (2020). Pendampingan Pemberdayaan Ibu-lbu Kelompok Wanita Tani Dalam Pemanfaatan Daun Sirih Sebagai Bahan Dasar Pembuatan Hand Sanitizer. Jurnal Abdimas, 4(2), 91-100.

Frank, Eibe, Mark Hall, Geoffrey Holmes, Richard Kirkby, Bernhard Pfahringer, lan H. Witten, and Len Trigg. 2009. "Weka-A Machine Learning Workbench for Data Mining." In Data Mining and Knowledge Discovery Handbook, 1269-77. Boston, MA: Springer US. https://doi.org/10.1007/978-0-387-09823-4_66.

Han, Jiawei, Micheline Kamber, and Jian Pei. 2012. Data Mining: Concepts and Techniques. Morgan Kaufmann Publishers. 3rd ed. Massachusetts: Morgan Kaufmann Publishers.

Iriyadi, I., Setiawan, B., \& Sutarti, S. (2017). Pelatihan Analisis Data Penelitian (Primer Dan Sekunder) Bagi Mahasiswa Kesatuan. Jurnal Abdimas, 1(1), 1-4.

Kementerian Pendidikan dan Kebudayaan Republik Indonesia. 2020. PERATURAN MENTERI PENDIDIKAN DAN KEBUDAYAAN REPUBLIK INDONESIA NOMOR 3 TAHUN 2020 TENTANG STANDAR NASIONAL PENDIDIKAN TINGGI.

Kurniawan, Donny, Anthony Anggrawan, and Hairani Hairani. 2020. "Graduation Prediction System On Students Using C4.5 Algorithm." MATRIK: Jurnal Manajemen, Teknik Informatika Dan Rekayasa Komputer 19 (2): 358-65. https://doi.org/10.30812/matrik.v19i2.685.

Meiriza, Allsela, Endang Lestari, Pacu Putra, Ayu Monaputri, and Dini Ayu Lestari. 2020. "Prediction Graduate Student Use Naive Bayes Classifier." In Proceedings of the Sriwijaya International Conference on Information Technology and Its Applications (SICONIAN 2019). Paris, France: Atlantis Press. https://doi.org/10.2991/aisr.k.200424.056.

Mulyana, M. (2012). Consumer Behaviour: Sukses Dengan Memahami Konsumen.

Mulyana, M., \& Puspitasari, R. (2014). Model Struktural Minat Berwirausaha Siswa SMK Di Kota Bogor. SNIT 2014, 1(1), 83-91.

Nafie Ali, Faisal Mohammed, and Abdelmoneim Ali Mohamed Hamed. 2018. "Usage Apriori and Clustering Algorithms in WEKA Tools to Mining Dataset of Traffic Accidents." Journal of Information and Telecommunication 2 (3): 231-45. https://doi.org/10.1080/24751839.2018.1448205.

Quinlan, J R. 1996. "Improved Use of Continuous Attributes in C4.5." Journal of Artificial Intelligence Research 4 (March): 77-90. https://doi.org/10.1613/jair.279.

Soleh, M., Sutarti, S., \& Rosita, S. I. (2020, May). The Effect of Human Resources Quality and Technology Adoption on the Quality of Financial Reporting (Evidence from MSMEs in Bogor). In 2nd International Seminar on Business, Economics, Social Science and Technology (ISBEST 2019) (pp. 199-203). Atlantis Press.

Solichin, Achmad. 2019. "Comparison of Decision Tree, Naïve Bayes and K-Nearest Neighbors for Predicting Thesis Graduation." In 2019 6th International Conference on Electrical Engineering, Computer Science and Informatics (EECSI), 217-22. IEEE. https://doi.org/10.23919/EECSI48112.2019.8977081.

Suhaimi, Nurafifah Mohammad, Shuzlina Abdul-Rahman, Sofianita Mutalib, Nurzeatul

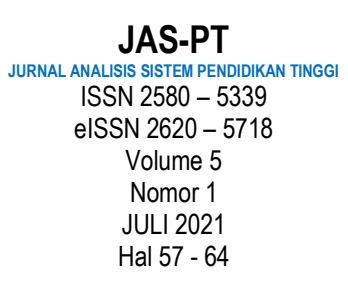

DOSEN INDONESIA SEMESTA 
Hamimah Abdul Hamid, and Ariff Md Ab Malik. 2019. "Review on Predicting Students' Graduation Time Using Machine Learning Algorithms." International Journal of Modern Education and Computer Science 11 (7): 1-13. https://doi.org/10.5815/ijmecs.2019.07.01.

Witten, lan H., Eibe Frank, and Mark A. Hall. 2011. Data Mining: Practical Machine Learning Tools and Techniques. 3rd ed. Massachusetts: Morgan Kaufmann.

Hal $57-64$

DOSEN INDONESIA SEMESTA 